\title{
Do Radiographic Parameters of Dysplasia Improve to Normal Ranges After Bernese Periacetabular Osteotomy?
}

\author{
Eduardo N. Novais MD, Stephen Duncan MD, Jeffrey Nepple MD, \\ Gail Pashos BS, Perry L. Schoenecker MD, John C. Clohisy MD
}

Published online: 19 September 2016

(C) The Association of Bone and Joint Surgeons (B) 2016

\begin{abstract}
Background The goal of periacetabular osteotomy (PAO) is to improve the insufficient coverage of the femoral head and achieve joint stability without creating secondary femoroacetabular impingement. However, the complex tridimensional morphology of the dysplastic acetabulum presents a challenge to restoration of normal radiographic parameters. Accurate acetabular correction is important to
\end{abstract}

One of the authors (JCC) has received grants from Zimmer (Warsaw, IN, USA) and Smith \& Nephew (Memphis, TN, USA); consulting fees from MicroPort Orthopedics, Inc (Arlington, TN, USA) and Zimmer Biomet (Warsaw, IN, USA); and publication royalties from Wolters Kluwer Health (Baltimore, MD, USA). One of the authors (SD) has received consulting fees from Smith \& Nephew and Biomet (Warsaw, IN, USA); and a grant from Stryker (Kalamazoo, MI, USA). One of the authors (JN) has received fees as a speaker, consultant, and for research from Smith \& Nephew and for research from Zimmer.

All ICMJE Conflict of Interest Forms for authors and Clinical Orthopaedics and Related Research ${ }^{\circledR}$ editors and board members are on file with the publication and can be viewed on request.

Each author certifies that his or her institution approved the human protocol for this investigation, that all investigations were conducted in conformity with ethical principles of research, and that informed consent for participation in the study was obtained.

This work was performed at the Department of Orthopedic Surgery, Washington University School of Medicine/Barnes-Jewish Hospital, St Louis, MO, USA.

\section{E. N. Novais}

Department of Orthopedic Surgery, Boston Children's Hospital, Boston, MA, USA

S. Duncan

Department of Orthopedic Surgery, University of Kentucky, Lexington, KY, USA

J. Nepple, G. Pashos, J. C. Clohisy

Department of Orthopedic Surgery, Washington University

School of Medicine/Barnes-Jewish Hospital, St Louis, MO, USA

achieve long-term function and pain improvement. There are limited data about the proportion of patients who have normal radiographic parameters restored after $\mathrm{PAO}$ and the factors associated with under- and overcorrection.

Questions/purposes (1) What is the proportion of patients undergoing PAO in which the acetabular correction as assessed by the lateral center-edge angle (LCEA), anterior center-edge angle (ACEA), acetabular inclination (AI), and extrusion index (EI) is within defined target ranges? (2) What patient and preoperative factors are associated with undercorrection of the acetabulum as defined by a LCEA $<$ $22^{\circ}$, a factor that has been reported to be associated with PAO failure at 10-year followup?

Methods Between January 2007 and December 2011 we performed 132 PAOs in 116 patients for treatment of symptomatic acetabular dysplasia. One patient with LeggCalvé-Perthes disease, one with multiple osteochondromatosis, and two with concomitant femoral osteotomy were excluded. A total of 128 hips (112 patients) were included. The hip cohort was $76 \%$ (97 of 128) female and the mean age at surgery was 28.5 years (SD 8.7 years). Correction of LCEA between $25^{\circ}$ and $40^{\circ}$, ACEA between $18^{\circ}$ and $38^{\circ}$, Tönnis angle between $0^{\circ}$ and $10^{\circ}$, and $\mathrm{EI} \leq$ $20 \%$ were defined as adequate based on normative values. Values lower than the established parameters were

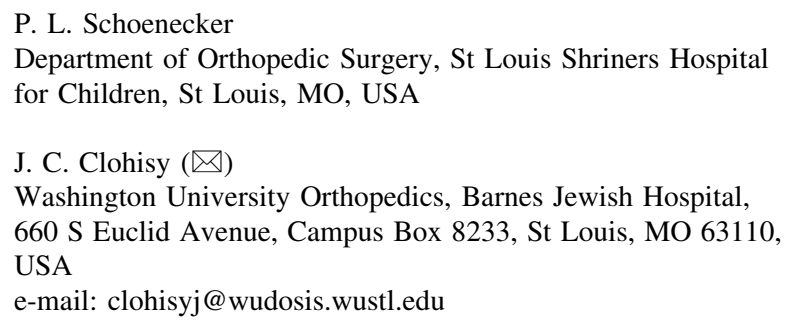


considered undercorrection for the LCEA and ACEA and those higher than the established values were considered overcorrection. Because postoperative LCEA $<22^{\circ}$ has been previously associated with $\mathrm{PAO}$ failure at a minimum of 10-year followup, in this study we sought to measure whether demographic factors including age, gender, body mass index, and severity of acetabular dysplasia assessed by preoperative LCEA, ACEA, AI, and EI were associated with undercorrection. Postoperative radiographs were obtained at minimum of 1 month after surgery (mean, 7 months; range, 1-44 months) and were measured by a professional research assistant and a hip reconstruction fellow not involved in the clinical care of the patients. No patient was lost to followup.

Results Of the 128 hips, the proportion of hips with radiographic parameters within the established range was $78 \%$ (100 hips) for the LCEA, 86\% (110 hips) for the ACEA, 89\% (114 hips) for the AI, and 80\% (102 hips) for the EI. For hips with an inadequate correction, the LCEA was more often undercorrected than overcorrected (20\% versus $2 \%$; $95 \%$ confidence interval [CI], 11\%-27\%; $\mathrm{p}<0.001$ ), whereas the ACEA was more often overcorrected than undercorrected ( $11 \%$ versus 3\%; 95\% CI, 1\%-15\%; $\mathrm{p}=0.03$ ) After adjusting for age, sex, body mass index, and preoperative radiographic parameters including ACEA, AI, and EI, we found that the preoperative LCEA was the only independent factor associated with a postoperative LCEA $<22^{\circ}$ (odds ratio, $0.92 ; 95 \%$ CI, 0.87-0.97; $p=0.003$ ), indicating that hips with lower preoperative LCEA were more likely to have a LCEA $<22^{\circ}$. For each additional degree of preoperative LCEA, the odds of LCEA $<22^{\circ}$ were reduced by $15 \%$.

Conclusions Acetabular correction after PAO performed by two experienced surgeons was adequate for individual radiographic parameters in most but not all hips. Hips with more severe dysplasia preoperatively are at higher risk for undercorrection as assessed by the LCEA. This intuitive information may help surgeons performing PAO in severely dysplastic hips plan for possible combined procedures including a femoral osteotomy if PAO alone does not allow for adequate correction of femoral head coverage and a congruous concentric hip. Further studies are planned to determine whether the long-term hip function and pain in patients whose hips were corrected within these established parameters will be improved in comparison to those that were under- or overcorrected.

Level of Evidence Level III, therapeutic study.

\section{Introduction}

Acetabular dysplasia is characterized by deficient anterior and lateral femoral head coverage, superolateral inclination of the joint surface, and a relative lateral position of the hip center [5, 22]. In acetabular dysplasia the reduced coverage of the femoral head creates shearing stress forces and overloads the anterolateral aspect of the acetabulum. This abnormal mechanical environment in the hip may lead to cartilage damage and hip osteoarthritis [1, 12, 15, 17]. Surgical treatment aims to reorient the acetabulum to improve the anterior and lateral coverage and reduce the contact pressure of the anterolateral acetabular rim $[15,22]$.

The Bernese periacetabular osteotomy (PAO) [11] is one of the most commonly performed reorientation procedures for the treatment of symptomatic acetabular dysplasia with well-reported improvement in hip pain and function $[1,13,24,30,31,36]$. The proportion of successful results after PAO, defined as preservation of the native hip without later THA has been reported to be affected by age at surgery, preoperative degree of degenerative joint disease, severity of symptoms including pain before surgery, and joint congruency $[9,13,22,24,25,30-32,36,40]$. The position of the acetabulum after PAO has also been reported to influence hip survivorship [1, 13, 32]. Both overcorrection [1, 32] and undercorrection $[13,31,32,36]$ have been associated with lower hip-specific outcome scores and progression to osteoarthritis after PAO. Specifically, undercoverage assessed by a lateral center-edge angle less than $22^{\circ}$ was reported as an independent factor associated with PAO failure defined by later progression of osteoarthrosis, THA, or high pain scores at minimum 10-year followup [1]. Acetabular dysplasia is a complex three-dimensional deformity and the reorientation possible may be dependent on patient-specific anatomic factors, which makes establishing universal correction guidelines difficult. Evidence concerning recommendations for specific radiographic parameters of acetabular correction is controversial and the proportion of instances when these parameters are met and identification of factors associated with achieving an adequate correction are limited [1, 13, 24, 26, 31, 32, 35].

In this retrospective study, we defined a target of acetabular correction for individual radiographic parameters based on reported normative values [7, 18, 21, 27, 33, 39] and we specifically asked: (1) What is the proportion of patients undergoing PAO in which the acetabular correction as assessed by the lateral center-edge angle (LCEA), anterior center-edge angle (ACEA), acetabular inclination (AI), and extrusion index (EI) is within defined target ranges? (2) What patient or preoperative factors are associated with undercorrection of the acetabulum as defined by LCEA $<22^{\circ}$, a factor that has been reported to be associated with PAO failure at 10-year followup? 


\section{Patients and Methods}

After institutional review board approval, we searched the Washington University prospectively collected joint preservation database to identify patients with the diagnosis of symptomatic acetabular dysplasia who underwent a PAO by the senior authors (JCC, PLS) between January 2007 and December 2011. During this period, we performed 132 PAOs in 116 patients. The indications for PAO included persistent hip and/or groin pain despite conservative treatment and radiographic evidence of acetabular dysplasia with a LCEA of Wiberg [39] of $<20^{\circ}$ on an AP pelvic radiograph and/or an ACEA lower than $15^{\circ}$ on a false profile view [21]. Contraindications for PAO included radiographic presence of severe hip osteoarthritis defined by higher than Tönnis Grade II [33]. One patient with Perthes-like deformity and one patient with multiple osteochondromatosis were excluded. Two additional patients who underwent an intertrochanteric femoral varusproducing osteotomy at the time of PAO were also excluded, leaving a total of 128 hips in 112 patients. The hip cohort was $76 \%$ (97 of 128) female and the mean age at surgery was 28.5 years (SD 8.7 years) (Table 1). The medical records were retrospectively reviewed for collection of demographic data including age, sex, and body mass index (BMI; $\mathrm{kg} / \mathrm{m}^{2}$ ) at the time of surgery.

Radiographic parameters assessed included measurement of the LCEA [39], ACEA [21], AI as described by Tönnis [33], and EI [14]. All patients in this study had preoperative and postoperative standing AP pelvis

Table 1. Demographic characteristics and preoperative and postoperative radiographic measurements for the entire cohort $(\mathrm{N}=128$ hips)

\begin{tabular}{lcl}
\hline Patient characteristics and radiographs & Mean & $\pm \mathrm{SD}$ \\
\hline Demographics & 29 & \pm 9 \\
Age (years) & 97 & 76 \\
Female sex (\%) & 28 & \pm 4 \\
Body mass index $\left(\mathrm{kg} / \mathrm{m}^{2}\right)$ & 67 & 53 \\
Right hip (\%) & 11 & \\
Preoperative measurements & 13 & \pm 10 \\
Lateral center-edge angle (degrees) & 18 & \pm 7 \\
Anterior center-edge angle (degrees) & 34 & \pm 10 \\
Acetabular inclination (degrees) & & \\
Extrusion index (\%) & 29 & \pm 6 \\
Postoperative measurements & 31 & \pm 7 \\
Lateral center-edge angle ${ }^{*}$ (degrees) & 4 & \pm 4 \\
Anterior center-edge angle ${ }^{*}$ (degrees) & 16 & \pm 7 \\
Acetabular inclination ${ }^{*}$ (degrees) & & \\
Extrusion index ${ }^{*}(\%)$ & & \\
\hline
\end{tabular}

*Significant change from preoperative measurement at the $1 \%$ significance level. radiographs performed with the beam centered at the level of the femoral head and false profile according to a previous described technique [21]. No specific software was used to compensate for potential pelvic tilt or rotation. Radiographic measurements were performed by a hip preservation surgeon fellow (SD) and a professional researcher (GP) who were not involved in the clinical care of the patients. The examiners were blinded to the goals of the acetabular reorientation at the time that the measurements were made. We did not determine the reliability of our radiographic measurements of the LCEA. In a previous study, the intraclass correlation coefficients (ICCs) for interobserver variability of the LCEA, ACEA, EI, and AI ranged from 0.82 to 1.0 [20]. Several studies have reported the interobserver reliability for those parameters with ICCs for LCEA ranging from 0.42 to 0.92 , AI from 0.45 to 0.85 , EI from 0.84 to 0.91 , and ACEA from 0.55 to 0.88 $[2-4,8,23,28]$ Postoperative radiographs obtained at a minimum of 1 month after surgery (mean, 7 months; range, 1-44 months) were used for the measurements. We assumed that there would be minimal change between the radiographic parameters after 1 month of surgery; however, it is possible that small differences could potentially result from variation of radiographic projection and healing of the osteotomy. Correction of LCEA between $25^{\circ}$ and $40^{\circ}$ [26, 34, 35, 38], ACEA between $18^{\circ}$ and $38^{\circ}[7,21]$, Tönnis angle between $0^{\circ}$ and $10^{\circ}[7,18,33]$, and $\mathrm{EI} \leq 20 \%$ $[7,18]$ were defined as the target ranges for radiographic correction after PAO based on previously published normative values [7, 18, 21, 27, 33, 39]. For the purpose of this study, values within the established targets were considered adequately corrected, whereas those inferior to the target were considered undercorrected and those above the target were considered overcorrected. Previous studies have suggested a correlation between adequate acetabular correction after $\mathrm{PAO}$ and long-term functional hip improvement $[1,13,32,36]$. Because most of these studies reported the LCEA as an independent predictor of functional improvement and hip survivorship after PAO $[1,13,35,36]$, we investigated whether patient-specific factors or preoperative radiographic parameters were associated with PAO undercorrection defined by LCEA < $22^{\circ}$. We chose this value based on a previous study showing that a LCEA $<22^{\circ}$ was an independent postoperative radiographic parameter predictive of PAO failure in a 10-year followup study [1].

\section{Statistical Analysis}

The proportion of hips that achieved hip correction target values with respect to LCEA, ACEA, AI, and EI was determined for each radiographic measure along with a 
95\% confidence interval. Multivariable general linear modeling was used to assess whether preoperative radiographic parameters were associated with undercorrection after PAO, defined by a postoperative LCEA $<22^{\circ}$ while controlling for age, sex, and BMI. Adjusted odds ratios with $95 \%$ confidence intervals were estimated for significant factors. Data were complete for all measurements in all hips. All tests were two-sided and p values $<0.05$ were considered significant.

\section{Results}

Of the 128 hips, the proportion of hips corrected with radiographic parameters within the established range was $78 \%$ (100 hips) for the LCEA, 86\% (110 hips) for the ACEA, 89\% (114 hips) for the AI, and 80\% (102 hips) for the EI (Table 2). For hips that did not hit the target, the LCEA (Fig. 1) was more often undercorrected than overcorrected $(20 \%$ versus $2 \%$; $95 \%$ confidence interval [CI], $11 \%-27 \%$; $\mathrm{p}<0.001$ ), whereas the ACEA (Fig. 2) was more often overcorrected than undercorrected (11\% versus $3 \%$; 95\% CI, 1\%-15\%; $\mathrm{p}=0.03$ ). For the AI we did not observe a difference in the proportion of patients who had postoperative values higher than the target value versus those who had lower values $(3 \%$ versus $8 \%$; $95 \%$ CI. $-2 \%$ to $11 \% ; \mathrm{p}=0.17)$.
After adjusting for age, sex, BMI, and preoperative radiographic parameters including $\mathrm{ACEA}, \mathrm{AI}$, and $\mathrm{EI}$, we found that the preoperative LCEA was the only independent factor associated with a postoperative LCEA $<22^{\circ}$ (odds ratio, 0.92; 95\% CI, 0.87-0.97; $\mathrm{p}=0.003$ ), indicating that hips with lower preoperative LCEA were more likely to have a LCEA $<22^{\circ}$ (Table 3 ). For each additional degree of preoperative LCEA, the odds of LCEA $<22^{\circ}$ were reduced by $15 \%$.

\section{Discussion}

The goals of PAO are to reorient the dysplastic acetabulum to improve femoral head coverage and joint stability while reducing pain and improving the function of the hip with the intention of slowing the progression or preventing symptomatic hip arthritis. Previous studies have reported on the outcomes after PAO, citing preoperative patient factors and postoperative radiographic parameters associated with failure $[1,9,11,13,22,24,30-32,34,36]$. Nevertheless, there are limited data guiding the range of radiographic parameters to be met after surgery $[13,25,30-32,36]$. General agreement exists that the acetabular inclination should be between $0^{\circ}$ and $10^{\circ}$ [7, 13, 26, 31, 35, 36] and postoperative EI should be $<20 \%[7,26,32]$. The recommended acetabular correction

Table 2. Proportion of hips that met the established target for postoperative parameter measurement for the entire cohort $(\mathrm{N}=128)$

\begin{tabular}{llll}
\hline Postoperative parameter measurement (target) & Frequency & Percent & $95 \%$ CI \\
\hline Lateral center-edge angle $\left(25^{\circ}-40^{\circ}\right)$ & 100 & 78 & $69.8 \%-84.7 \%$ \\
Anterior center- edge angle $\left(18^{\circ}-38^{\circ}\right)$ & 110 & 86 & $78.4 \%-91.2 \%$ \\
Acetabular inclination $\left(0^{\circ}-10^{\circ}\right)$ & 114 & 89 & $82.0 \%-93.7 \%$ \\
Extrusion index $(\leq 20)$ & 102 & 80 & $71.5 \%-86.1 \%$ \\
\hline
\end{tabular}

$\mathrm{CI}=$ confidence interval.

Fig. 1 The distribution of postoperative measurements of LCEA shows that the majority of patients were corrected within the target range. For hips with an inadequate correction, the LCEA was more often undercorrected than overcorrected $(20 \%$ versus $2 \%$; $95 \%$ CI, $11 \%-27 \%$; $<<0.001)$.

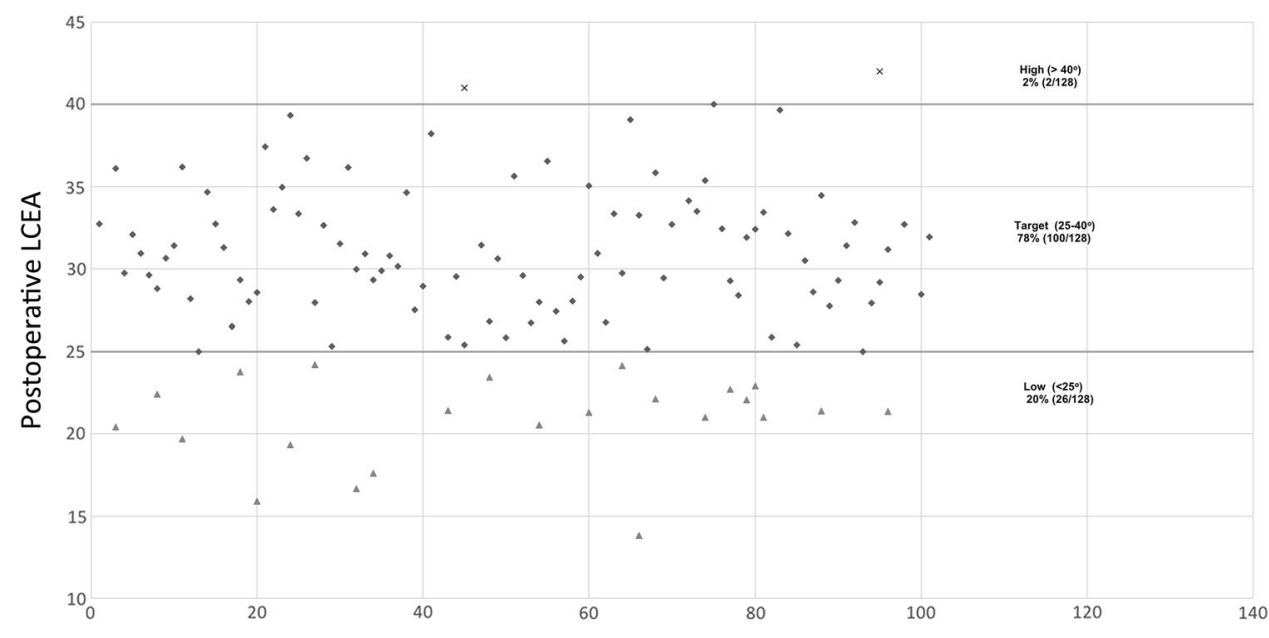


Fig. 2 The distribution of postoperative measurements of ACEA shows that the majority of patients were corrected within the target range. For hips with an inadequate correction, the ACEA was more often overcorrected than undercorrected ( $11 \%$ versus $3 \%$; $95 \%$ CI, $1 \%$ $15 \% ; \mathrm{p}=0.03)$

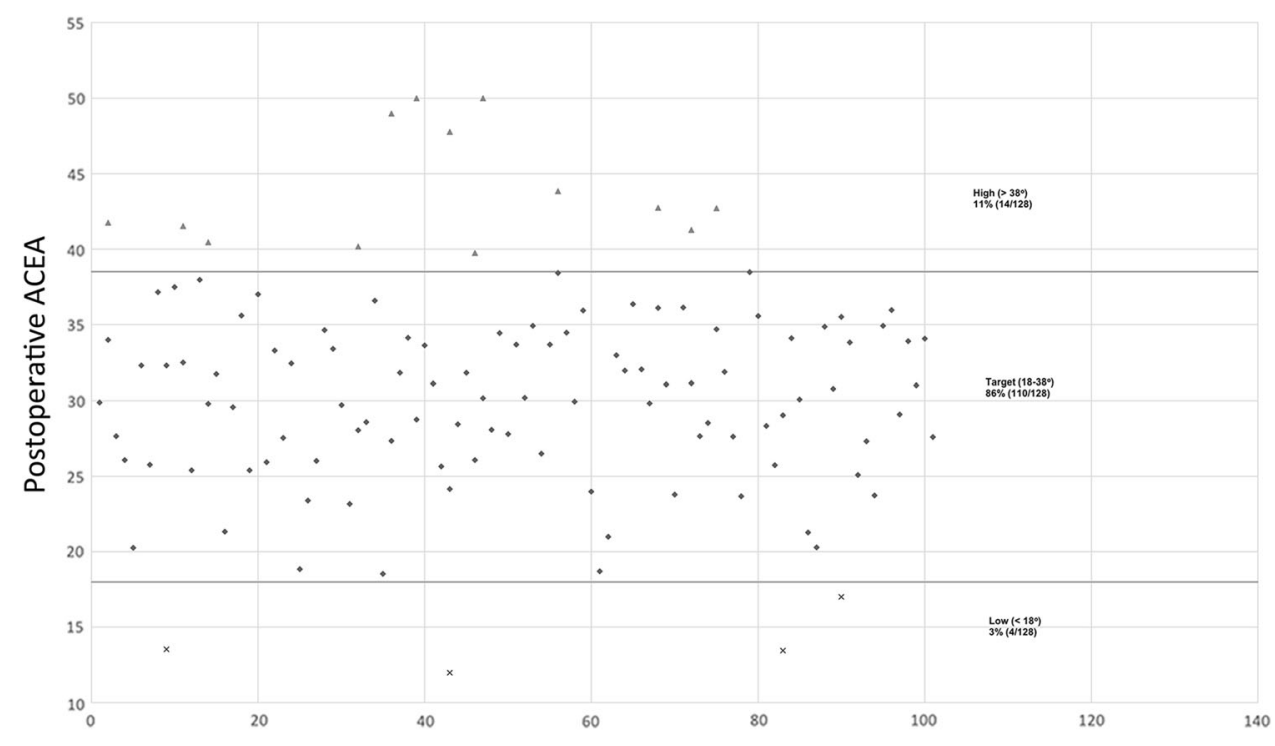

Table 3. Univariate and multivariable analysis for postoperative undercorrection assessed by LCEA $<22^{\circ}$

\begin{tabular}{|c|c|c|c|c|c|c|c|c|}
\hline \multirow{2}{*}{$\begin{array}{l}\text { Preoperative measurement } \\
\text { LCEA (degrees) }\end{array}$} & \multicolumn{2}{|c|}{$\begin{array}{l}\text { Postoperative } \\
\text { LCEA }<22^{\circ} \\
(\mathrm{n}=16)\end{array}$} & \multicolumn{2}{|c|}{$\begin{array}{l}\text { Postoperative LCEA } \geq 22^{\circ} \\
(\mathrm{n}=112)\end{array}$} & \multirow{2}{*}{$\begin{array}{l}\text { Unadjusted } \\
\mathrm{p} \text { value }\end{array}$} & \multirow{2}{*}{$\begin{array}{l}\text { Adjusted } \\
\text { p value } \\
0.003\end{array}$} & \multirow{2}{*}{$\begin{array}{l}\text { OR } \\
0.92\end{array}$} & \multirow{2}{*}{$\begin{array}{l}95 \% \mathrm{CI} \\
0.87 \%-0.97\end{array}$} \\
\hline & 3 & \pm 11 & 12 & \pm 9 & & & & \\
\hline Anterior center-edge angle (degrees) & 13 & \pm 14 & 13 & \pm 11 & 0.80 & 0.64 & 0.99 & $0.94 \%-1.04$ \\
\hline Acetabular inclination (degrees) & 21 & \pm 9 & 18 & \pm 7 & 0.06 & 0.06 & 1.08 & $1 \%-1.18$ \\
\hline Extrusion index $(\%)$ & 39 & \pm 9 & 34 & \pm 10 & 0.06 & 0.10 & 1.05 & $0.99 \%-1.1$ \\
\hline \multicolumn{9}{|l|}{ Demographics } \\
\hline Age (years) & 26 & \pm 8 & 29 & \pm 9 & 0.2 & & & \\
\hline Sex $(\%$ female $)$ & $12(76 \%)$ & $76 \%$ & 85 & $(76 \%)$ & 0.94 & & & \\
\hline Body mass index $\left(\mathrm{kg} / \mathrm{m}^{2}\right)$ & 24 & \pm 4 & 25 & \pm 4 & 0.51 & & & \\
\hline
\end{tabular}

LCEA = lateral center-edge angle; $\mathrm{OR}$ = odds ratio from multivariable logistic model; $\mathrm{CI}$ = confidence interval; unadjusted $\mathrm{p}$ value corresponds to univariate logistic regression analysis; adjusted $\mathrm{p}$ value corresponds to the multivariable logistic models controlling for age, sex, and body mass index.

in terms of the LCEA, however, remains controversial $[1,30,31,35,36]$. In this study we established a target range of radiographic parameters based on a normal range $[7,18]$ and determined the proportion of hips that were corrected within this established range. We also investigated factors predictive of undercorrection, defined as LCEA $<22^{\circ}$, which has been reported to be associated with PAO failure at minimum 10-year followup [1].

There were several limitations to this study. First, all PAOs were performed by two experienced surgeons, which is a concern for generalizing our findings, because the decision about the correction in each case was based on the individual surgeon's perspective. The correction was assessed intraoperatively by fluoroscopy, which has been shown to have a high correlation with postoperative plain radiographs for the LCEA, ACEA, and AI [20]. It is possible that surgeons with less experience performing PAO may not achieve the same proportion of correction reported in this study. However, this study includes a consecutive series of patients past the surgeon's learning curve associated with PAO. Furthermore, the risk of selection bias is reduced by inclusion of almost all patients undergoing PAO during the study period. Second, we do not present any data respective to the correction of acetabular position and the patient's reported functional outcome. We feel that assessment of the correction and its impact on outcome of PAO surgery will require a long-term followup study because development of osteoarthritis (the most important outcome) is an indolent process that may take years to develop. The association of functional outcome with radiographic correction is beyond the scope of this study but is the focus of one of our future investigations. Third, the target ranges used in this study were retrospectively determined based on normative values. During surgery, 
definitive correction may be influenced by the degree of displacement of the fragment and the hip ROM with the goal of keeping the hip flexion at least $90^{\circ}$ and internal rotation at least $20^{\circ}$. A prospective study, with the range of desired correction established before patients are enrolled, would better address the question about frequency of achieving the target range and reasons related to clinical failure. Fourth, there are radiographic parameters reflecting the three-dimensional structure of the hip such as acetabular sector angles and acetabular version that were not included in the current study. Although estimation of femoral head coverage by the acetabular wall index and retroversion signs could be added to this analysis, these parameters are highly influenced by inclination of the pelvis [29]. Although the parameters investigated in the current study may also be affected by pelvic tilt and rotation as well, Lee et al. [19] showed that variations in pelvic tilt as much as $20^{\circ}$ did not have a substantial effect on the LCEA. In addition, we did not assess femoral morphology including neck-shaft angle and anteversion, which may also be considered in surgical planning for PAO. Currently, we are designing a low-radiation CT protocol to help PAO planning and assess the postoperative correction, which will allow us to investigate these parameters more precisely. Fifth, another potential limitation of our study is the previous reported variability of the LCEA and AI measurements around $\pm 5^{\circ}[16,35,37]$, which is an inherent limitation of all studies evaluating the radiographic results of PAO. Finally we used radiographs obtained between 1 and 44 months postsurgery. We assumed that there would be minimal change between the radiographic parameters after 1 month of surgery; however, we acknowledge that small differences could potentially result from variation of radiographic projection and healing or remodeling of the PAO.

In this study of 128 dysplastic hips corrected by PAO performed by two experienced surgeons, the radiographic correction was within the established target in 78\% (100 of 128 ) of the hips for the LCEA, $89 \%$ (114 of 128) for the AI, 86\% (110 of 128) for the ACEA, and 80\% (102 of 128) for the EI. Evaluation of the correction during PAO involves radiographic parameters (LCEA, AI, ACEA, EI, medialization, and the acetabular version) and hip motion with the goal of preserving $90^{\circ}$ of flexion and $20^{\circ}$ of internal rotation in flexion $[1,6,11,13,22,26,31,35]$. A previous study [1] showed that only $6 \%$ of the hips had a postoperative radiograph meeting all six radiographic parameters including total, anterior, and posterior femoral coverage; LCEA; AI; and EI. During surgery, often the goal of achieving a horizontal acetabular sourcil (AI close to zero) takes precedence because in the dysplastic acetabulum, the acetabular weightbearing zone is smaller [15] and it is possible that when the AI is neutral, the
LCEA may still be lower than the normal range of $25^{\circ}$. If the fragment is moved into further abduction, the LCEA would increase; however, the AI would become negative, which increases the risk for impingement. In this study, the AI was the parameter with the largest number of cases achieving the target zone; however, correction of AI with values lower than the target (negative values) was found in $8 \%$ of the hips. In a previous study, correction of the AI between $0^{\circ}$ and $10^{\circ}$ was possible in almost every PAO, although the specific proportion was not provided [35]. In our study, when the established targets were not met, undercorrection was more often observed than overcorrection for the LCEA. In contrast, we noticed that when the targets were not met for the ACEA, more often it was because of overcoverage than undercoverage. Our findings show that as a result of the complex morphology of the dysplastic acetabulum, it is unlikely that PAO would correct each radiographic parameter to a normal range in every patient. Further studies will be necessary to establish whether specific postoperative radiographic parameters including the LCEA, ACEA, AI, EI, acetabular version, and joint medialization- or a combination of all these parameters- are associated with functional outcomes and survivorship after PAO.

We found that preoperative LCEA was an independent factor associated with undercorrection defined as LCEA < $22^{\circ}$, a previously established threshold for PAO failure at minimum 10-year followup [1]. Undercorrection may not allow for restoration of a healthy mechanical environment in the joint and has been consistently associated with PAO failure [1, 13, 31, 32, 36]. The definition of undercorrection is controversial. Hartig-Andreasen et al. recommended LCEA between $30^{\circ}$ and $40^{\circ}$ because the risk of PAO failure (conversion to THA) was doubled if the postoperative LCEA was not between this narrow interval [13]. However, the authors did not discuss whether undercorrection versus overcorrection was more likely associated with PAO failure. We feel that this range of LCEA is too restrictive. In fact, in a previous study from the same group proposing $30^{\circ}$ to $40^{\circ}$ as the ideal range of correction of LCEA, a range between $23^{\circ}$ and $36^{\circ}$ was considered optimal because the correction was not always possible to achieve given the spectrum of acetabular dysplasia [35]. Steppacher et al. [32] showed that an undercorrected hip with an EI $>20 \%$ is at higher risk to develop osteoarthritis at a minimum 20-year followup. Troelsen et al. [36] showed that undercorrection assessed by a residual lateral translation of the femoral head $\geq 2.0 \mathrm{~cm}$ was a predictor of THA after PAO at a mean followup of 7 years. Our data suggest that in patients with a more severe dysplastic acetabulum (lower preoperative LCEA), the ability to achieve adequate coverage of the femoral head in terms of LCEA is more challenging. Although seemingly intuitive, 
this finding may help the surgeon plan for a potential femoral osteotomy as previously recommended [10] in cases of severe and complex dysplasia if adequate coverage of the femoral head is not obtained after PAO alone.

Previous studies have shown that achievement of adequate acetabular correction after PAO is important for long-term clinical success [1, 13, 32, 36]. In this study, adequate radiographic correction after PAO performed by two experienced surgeons was achieved more than $80 \%$ of the time for individual radiographic parameters. Our findings showed that although reorientation of the acetabulum through PAO improves coverage of the femoral head, as a result of the abnormal anatomy of the dysplastic acetabulum, it may not allow for restoration of all normal radiographic parameters in every patient. Future studies are planned to determine the association between radiographic correction and survivorship and functional outcomes after PAO.

Acknowledgments We thank Patricia Miller MS, for the statistical analysis of our study.

\section{References}

1. Albers CE, Steppacher SD, Ganz R, Tannast M, Siebenrock KA. Impingement adversely affects 10 -year survivorship after periacetabular osteotomy for DDH. Clin Orthop Relat Res. 2013;471:1602-1614.

2. Anderson LA, Gililland J, Pelt C, Linford S, Stoddard GJ, Peters CL. Center edge angle measurement for hip preservation surgery: technique and caveats. Orthopedics. 2011;34:86.

3. Carlisle JC, Zebala LP, Shia DS, Hunt D, Morgan PM, Prather H, Wright RW, Steger-May K, Clohisy JC. Reliability of various observers in determining common radiographic parameters of adult hip structural anatomy. Iowa Orthop J. 2011;31:52-58.

4. Carroll KL, Murray KA, MacLeod LM, Hennessey TA, Woiczik MR, Roach JW. Measurement of the center edge angle and determination of the Severin classification using digital radiography, computer-assisted measurement tools, and a Severin algorithm: intraobserver and interobserver reliability revisited. $J$ Pediatr Orthop. 2011;31:e30-e35.

5. Clohisy JC, Barrett SE, Gordon JE, Delgado ED, Schoenecker PL. Medial translation of the hip joint center associated with the Bernese periacetabular osteotomy. Iowa Orthop J. 2004;24:4348.

6. Clohisy JC, Barrett SE, Gordon JE, Delgado ED, Schoenecker PL. Periacetabular osteotomy for the treatment of severe acetabular dysplasia. J Bone Joint Surg Am. 2005;87:254-259.

7. Clohisy JC, Carlisle JC, Beaule PE, Kim YJ, Trousdale RT, Sierra RJ, Leunig M, Schoenecker PL, Millis MB. A systematic approach to the plain radiographic evaluation of the young adult hip. J Bone Joint Surg Am. 2008;90(Suppl 4):47-66.

8. Clohisy JC, Carlisle JC, Trousdale R, Kim YJ, Beaule PE, Morgan P, Steger-May K, Schoenecker PL, Millis M. Radiographic evaluation of the hip has limited reliability. Clin Orthop Relat Res. 2009;467:666-675.

9. Clohisy JC, Schutz AL, St John L, Schoenecker PL, Wright RW. Periacetabular osteotomy: a systematic literature review. Clin Orthop Relat Res. 2009;467:2041-2052.
10. Ganz R, Horowitz K, Leunig M. Algorithm for femoral and periacetabular osteotomies in complex hip deformities. Clin Orthop Relat Res. 2010;468:3168-3180.

11. Ganz R, Klaue K, Vinh TS, Mast JW. A new periacetabular osteotomy for the treatment of hip dysplasias. Technique and preliminary results. Clin Orthop Relat Res. 1988;232:26-36.

12. Harris WH. Etiology of osteoarthritis of the hip. Clin Orthop Relat Res. 1986;213:20-33.

13. Hartig-Andreasen C, Troelsen A, Thillemann TM, Soballe K. What factors predict failure 4 to 12 years after periacetabular osteotomy? Clin Orthop Relat Res. 2012;470:2978-2987.

14. Heyman $\mathrm{CH}$, Herndon $\mathrm{CH}$. Legg-Perthes disease; a method for the measurement of the roentgenographic result. $J$ Bone Joint Surg Am. 1950;32:767-778.

15. Hipp JA, Sugano N, Millis MB, Murphy SB. Planning acetabular redirection osteotomies based on joint contact pressures. Clin Orthop Relat Res. 1999;364:134-143.

16. Jacobsen S, Sonne-Holm S, Lund B, Soballe K, Kiaer T, Rovsing $\mathrm{H}$, Monrad H. Pelvic orientation and assessment of hip dysplasia in adults. Acta Orthop Scand. 2004;75:721-729.

17. Klaue K, Durnin CW, Ganz R. The acetabular rim syndrome. A clinical presentation of dysplasia of the hip. J Bone Joint Surg Br. 1991;73:423-429.

18. Laborie LB, Engesaeter IO, Lehmann TG, Sera F, Dezateux C, Engesaeter LB, Rosendahl K. Radiographic measurements of hip dysplasia at skeletal maturity-new reference intervals based on 2,038 19-year-old Norwegians. Skeletal Radiol. 2013;42:925935.

19. Lee YK, Chung CY, Koo KH, Lee KM, Kwon DG, Park MS. Measuring acetabular dysplasia in plain radiographs. Arch Orthop Trauma Surg. 2011;131:1219-1226.

20. Lehmann CL, Nepple JJ, Baca G, Schoenecker PL, Clohisy JC. Do fluoroscopy and postoperative radiographs correlate for periacetabular osteotomy corrections? Clin Orthop Relat Res. 2012;470:3508-3514.

21. Lequesne M, Djian A. [New radiographic angles for the study of the hip. The 'false profile' of the pelvis] [in French]. Vie Med. 1961;42:1629-1641.

22. Leunig M, Siebenrock KA, Ganz R. Rationale of periacetabular osteotomy and background work. Instr Course Lect. 2001;50:229-238.

23. Mast NH, Impellizzeri F, Keller S, Leunig M. Reliability and agreement of measures used in radiographic evaluation of the adult hip. Clin Orthop Relat Res. 2011;469:188-199.

24. Matheney T, Kim YJ, Zurakowski D, Matero C, Millis M. Intermediate to long-term results following the bernese periacetabular osteotomy and predictors of clinical outcome: surgical technique. J Bone Joint Surg Am. 2010;92(Suppl 1):115-129.

25. Millis MB, Kain M, Sierra R, Trousdale R, Taunton MJ, Kim YJ, Rosenfeld SB, Kamath G, Schoenecker P, Clohisy JC. Periacetabular osteotomy for acetabular dysplasia in patients older than 40 years: a preliminary study. Clin Orthop Relat Res. 2009; 467:2228-2234.

26. Millis MB, Siebenrock KA, Session P. Report of breakout session: Defining parameters for correcting the acetabulum during a pelvic reorientation osteotomy. Clin Orthop Relat Res. 2012;470:3453-3455.

27. Murphy SB, Ganz R, Muller ME. The prognosis in untreated dysplasia of the hip. A study of radiographic factors that predict the outcome. J Bone Joint Surg Am. 1995;77:985-989.

28. Nelitz M, Guenther KP, Gunkel S, Puhl W. Reliability of radiological measurements in the assessment of hip dysplasia in adults. Br J Radiol. 1999;72:331-334.

29. Siebenrock KA, Kalbermatten DF, Ganz R. Effect of pelvic tilt on acetabular retroversion: a study of pelves from cadavers. Clin Orthop Relat Res. 2003;407:241-248. 
30. Siebenrock KA, Leunig M, Ganz R. Periacetabular osteotomy: the Bernese experience. Instr Course Lect. 2001;50:239-245.

31. Siebenrock KA, Scholl E, Lottenbach M, Ganz R. Bernese periacetabular osteotomy. Clin Orthop Relat Res. 1999;363:9-20.

32. Steppacher SD, Tannast M, Ganz R, Siebenrock KA. Mean 20year followup of Bernese periacetabular osteotomy. Clin Orthop Relat Res. 2008;466:1633-1644.

33. Tönnis D. Congenital Dysplasia and Dislocation of the Hip in Children and aAdults. Berlin, Germany: Springer; 1987.

34. Troelsen A. Surgical advances in periacetabular osteotomy for treatment of hip dysplasia in adults. Acta Orthop Suppl. 2009;80:1-33.

35. Troelsen A, Elmengaard B, Romer L, Soballe K. Reliable angle assessment during periacetabular osteotomy with a novel device. Clin Orthop Relat Res. 2008;466:1169-1176.
36. Troelsen A, Elmengaard B, Soballe K. Medium-term outcome of periacetabular osteotomy and predictors of conversion to total hip replacement. J Bone Joint Surg Am. 2009;91:2169-2179.

37. Troelsen A, Jacobsen S, Romer L, Soballe K. Weightbearing anteroposterior pelvic radiographs are recommended in DDH assessment. Clin Orthop Relat Res. 2008;466:813-819.

38. Trumble SJ, Mayo KA, Mast JW. The periacetabular osteotomy. Minimum 2 year followup in more than 100 hips. Clin Orthop Relat Res. 1999;363:54-63.

39. Wiberg G. Studies on dysplastic acetabulum and congenital subluxation of the hip joint: with special reference to the complication of osteoarthritis. Acta Chir Scand Suppl. 1939;58:7-135.

40. Yasunaga Y, Yamasaki T, Matsuo T, Ishikawa M, Adachi N, Ochi M. Crossover sign after rotational acetabular osteotomy for dysplasia of the hip. J Orthop Sci. 2010;15:463-469. 